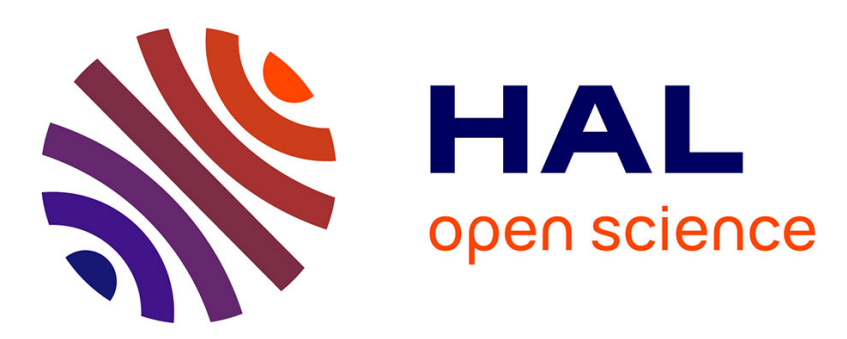

\title{
DISLOCATION MOBILITY IN ALKALI HALIDE CRYSTALS AT LOW TEMPERATURES
}

\author{
E. Gutmanas
}

\section{To cite this version:}

E. Gutmanas. DISLOCATION MOBILITY IN ALKALI HALIDE CRYSTALS AT LOW TEMPERATURES. Journal de Physique Colloques, 1976, 37 (C7), pp.C7-595-C7-600. 10.1051/jphyscol:19767139 . jpa-00216863

\section{HAL Id: jpa-00216863 https://hal.science/jpa-00216863}

Submitted on 1 Jan 1976

HAL is a multi-disciplinary open access archive for the deposit and dissemination of scientific research documents, whether they are published or not. The documents may come from teaching and research institutions in France or abroad, or from public or private research centers.
L'archive ouverte pluridisciplinaire HAL, est destinée au dépôt et à la diffusion de documents scientifiques de niveau recherche, publiés ou non, émanant des établissements d'enseignement et de recherche français ou étrangers, des laboratoires publics ou privés. 


\title{
DISLOCATION MOBILITY IN ALKALI HALIDE CRYSTALS AT LOW TEMPERATURES
}

\author{
E. Y. GUTMANAS \\ Department of Materials Engineering, Technion-Israel \\ Institute of Technology, Haifa, Israel
}

\begin{abstract}
Résumé. - La variation de la vitesse des dislocations avec la contrainte de scission appliquée a été mesurée à basse température dans des cristaux purs de $\mathrm{NaCl}, \mathrm{LiF}$ et $\mathrm{KI}$. La dépendance en température de la contrainte de scission résolue a été étudiée jusqu'à $4,2 \mathrm{~K}$ avec les mêmes cristaux et également avec des cristaux purs de $\mathrm{KCl}, \mathrm{KBr}$ et $\mathrm{RbI}$. Les résultats obtenus sont discutés brièvement.
\end{abstract}

Abstract. - Dislocation velocity dependences on applied shear stress were measured in pure $\mathrm{NaCl}, \mathrm{LiF}$ and $\mathrm{KI}$ crystals at low temperatures. Temperature dependences of the critical resolved shear stress (down to $4.2 \mathrm{~K}$ ) of the same crystals and also of pure $\mathrm{KCl}, \mathrm{KBr}$ and $\mathrm{RbI}$ were studied.

The results obtained are briefly discussed.

1. Introduction. - The plastic strain rate $\dot{\varepsilon}_{\mathrm{p}}$ may be expressed as

$$
\dot{\varepsilon}_{\mathrm{p}}=\rho \mathbf{b} v \text {, }
$$

where $\rho$ is the density of mobile dislocations, $\mathbf{b}$ is the Burgers vector and $v$ is the average dislocation velocity. $\rho$ and $v$ should depend on interaction of moving dislocations with phonon and electron subsystems and with various types of barriers, connected both with the periodical structure of crystals (Peierls barrier) and with lattice defects (impurities, other dislocations, etc.). Examination of $v$ and $\rho$ dependences on various parameters can make it possible to reveal the mechanisms of motion, drag and multiplication of dislocations. When these mechanisms are known, the plastic behavior of crystals (for $\dot{\varepsilon}_{\mathrm{p}}>0$ ) can be predicted and probably changed in a controlled way.

Studies of dislocation velocity $v$ dependence on applied shear stress $\tau$ in a wide range of $v$ in alkali halide crystals have shown [1-4] that in these crystals $v$ is very sensitive to $\tau$ in the low-velocity region $\left(v<10^{2} \mathrm{~cm} / \mathrm{s}\right.$ ) increasing by many orders of magnitude, following a relatively small increase of the stress. In the high velocity region $\left(v>10^{-2} v_{\mathrm{s}}\right.$, where $v_{\mathrm{s}}$ is the sound velocity) a linear dependence of $v$ on $\tau$ has been observed. It has also been shown that in the lowvelocity region $v$ is very sensitive to divalent cation impurities concentration $c_{\mathrm{i}}$. Small additions of such impurities $(10 \div 100 \mathrm{ppm})$ decrease $v$ by many orders of magnitude. In the high-velocity region $v$ is insensitive to $c_{\mathbf{i}}$.

The data for the $v$ dependence on $\tau$ in alkali halides were obtained mainly in the room temperature region. There are experimental results of the $v$ on $T$ dependence for the low-velocity region in $\mathrm{NaCl}$ of high purity $\left(c_{\mathbf{i}}<10 \mathrm{ppm}\right) \quad[5]$ and in pure $\mathrm{NaCl}$ $\left(c_{\mathrm{i}} \approx 10 \mathrm{ppm}\right.$ ) [6] down to $77 \mathrm{~K}$ and for the highvelocity region in heavily $\gamma$-irradiated $\left(10^{8} \mathrm{rad}\right)$ $\mathrm{NaCl}$ [7].

An investigation of the mobile dislocation density $\rho$ dependence on $\tau, T$ and $c_{\mathrm{i}}$ is rather complicated because of difficulties to separate between the mobile and immobile dislocations in the slip bands already at the beginning of plastic deformation. Usually the density of all dislocations in slip bands is measured. That is why $v$ is the main characteristic used to describe the plastic behavior of crystals. It is also a fact that at room temperature at a stress $\tau$ equal to the critical resolved shear stress $\tau_{s} v$ is relatively low $\left(10^{-5} \div 10^{-3} \mathrm{~cm} / \mathrm{s}\right)$ [1-4]. It means that stresses corresponding to a low $v$ produce enough mobile dislocations to get $\dot{\varepsilon}_{\mathrm{p}}>0$ (i. e. a slope change of the stress-strain curve). In [5] and [6] it has been observed that at low temperatures $\tau_{\mathrm{s}}$ corresponds to higher $v$.

In the present work $v(T)$ dependences in wide range of $v$ (and $\tau$ ) in pure $\mathrm{NaCl}, \mathrm{LiF}$ and $\mathrm{KI}$ were studied at low temperatures (down to $4.2 \mathrm{~K}$ in $\mathrm{NaCl}$ and down to $77 \mathrm{~K}$ in $\mathrm{LiF}$ and $\mathrm{KI}$ ). Temperature dependences of the critical resolved shear stress (down to $4.2 \mathrm{~K}$ ) of the same crystals and also of pure $\mathrm{KCl}, \mathrm{KBr}$ and $\mathrm{RbI}$ were measured.

2. Experimental details. - Investigations were made on pure annealed $\mathrm{NaCl}, \mathrm{LiF}, \mathrm{KI}, \mathrm{KCl}, \mathrm{KBr}$ and $\mathrm{RbI}$ single crystals. The total content of divalent impurities present did not exceed $30 \mathrm{ppm}$ for $\mathrm{RbI}$ and $10 \mathrm{ppm}$ for the other crystals. A pulse loading method and etch-pit technique were used to determine the velocities of individual dislocations $v$ as a function of applied shear stress $\tau$. The procedures for annealing, 
introducing fresh dislocations and for pulse loading were in principle the same, as those previously described [2]. Etchants of $50 \%$ formic acid and $50 \%$ acetic acid for $\mathrm{NaCl}$, water with $\mathrm{FeCl}_{3}$ for $\mathrm{LiF}$ [1] and of hexyl alcohol saturated with $\mathrm{CdI}_{2}$ [8] for KI were used in order to reveal dislocations. The density of grown-in dislocations was not higher than $10^{4} \mathrm{~cm}^{-2}$ and the average size of subgrains where displacements of fresh dislocations were measured was $>1 \mathrm{~mm}^{2}$. The studies of the critical resolved shear stress $\tau_{\mathrm{s}}$ were performed on an Instron testing machine at a strain rate

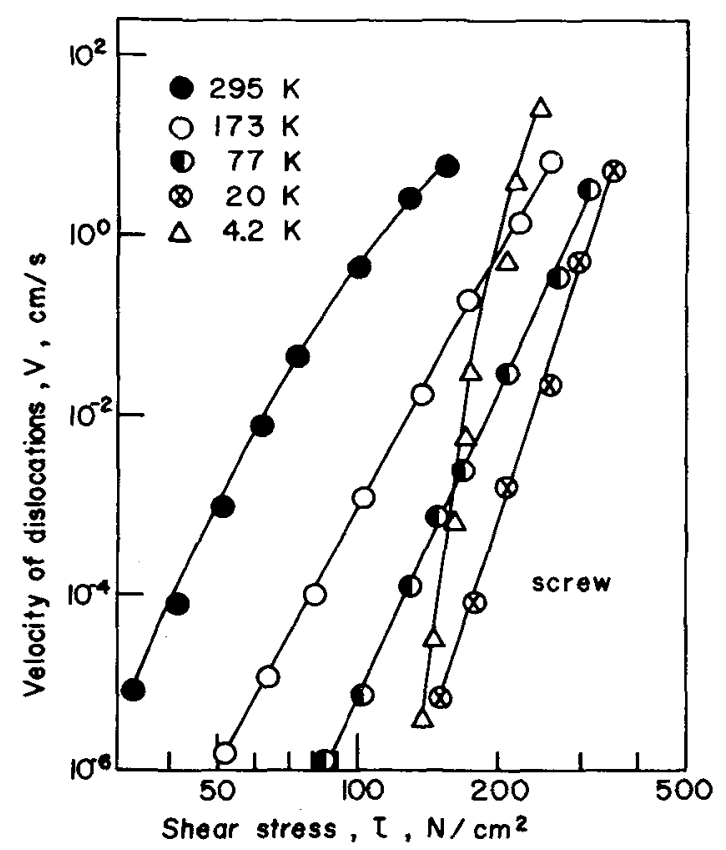

a)

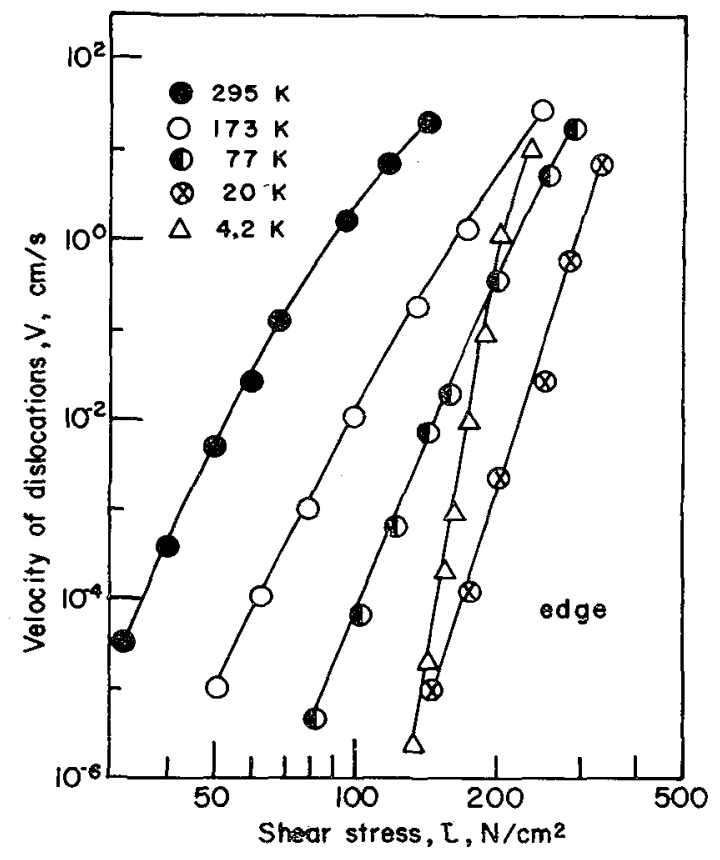

b)

FIG. 1. - Dependence of average velocity $v$ of screw $(a)$ and edge (b) dislocations on applied shear stress $\tau$ in $\mathrm{NaCl}$ (lowvelocity range, $\lg v-\lg \tau$ scale) at various temperatures. of about $2 \times 10^{-5} \mathrm{~s}^{-1}$. The samples were tested in compression. $\tau_{\mathrm{s}}$ was determined as the beginning of a slope change of the stress-strain curve.

3. Experimental results and discussion. - The results of dislocation velocity measurements both edge and srew dislocations at 4.2,20,77, 173 and $295 \mathrm{~K}$ in pure $\mathrm{NaCl}$ are presented in figures $1 a$ and $1 b$ (lowvelocity range, $\log v-\log \tau$ scale) and in figures $2 a$ and $2 b$ (high velocity range, $v-\tau$ scale). The results of

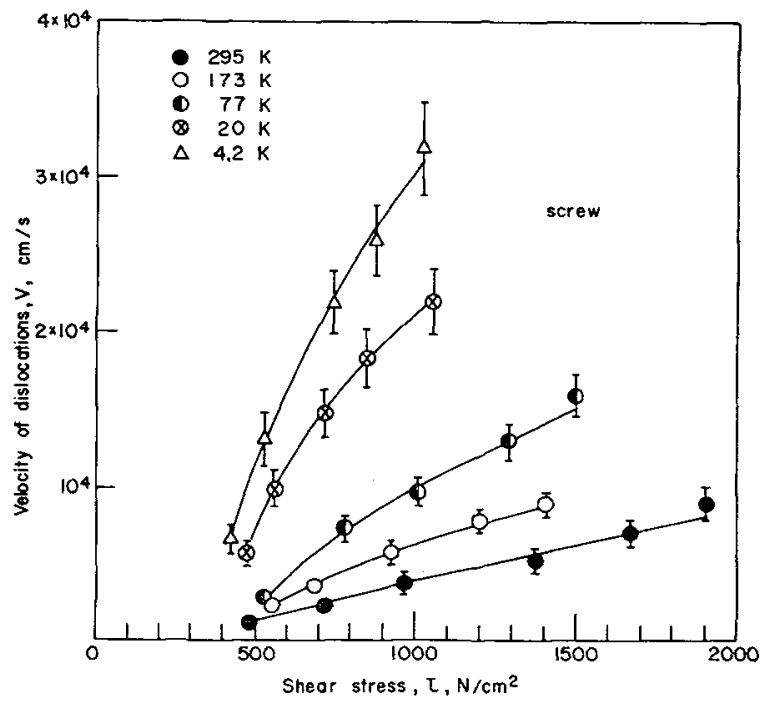

a)

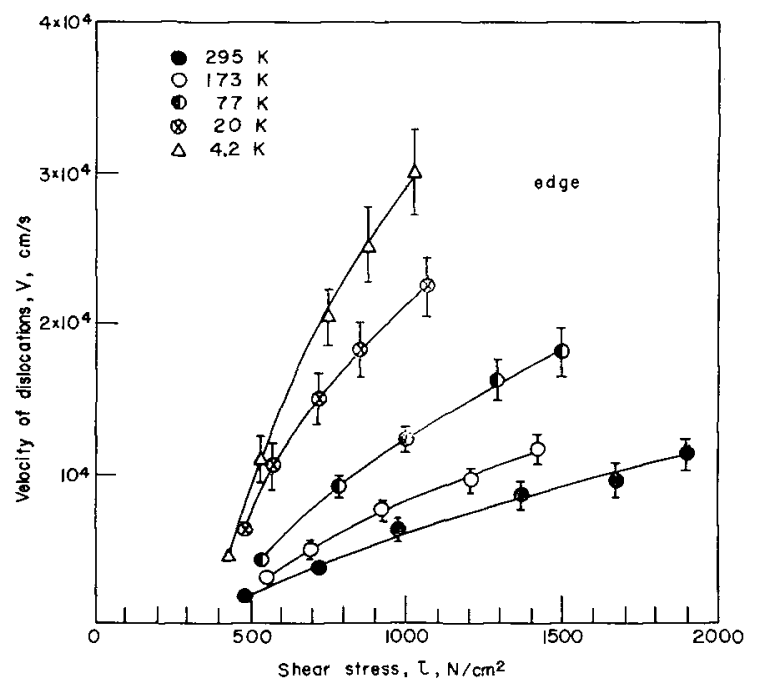

b)

Fig. 2. - Dependence of average velocity $v$ of screw (a) and edge (b) dislocations on applied shear stress $\tau$ in $\mathrm{NaCl}$ (highvelocity range) at various temperatures.

$v(\tau)$ measurements both edge and screw-dislocations at 77,173 and $295 \mathrm{~K}$ in pure $\mathrm{LiF}$ and $\mathrm{KI}$ are presented in figures 3 and 4 correspondingly. Every point of $v(\tau)$ dependences corresponds to an average velocity of $50 \div 100$ freshly introduced dislocations, which during their motion do not encounter any subgrain boundaries or other regions with high dislocation density. 


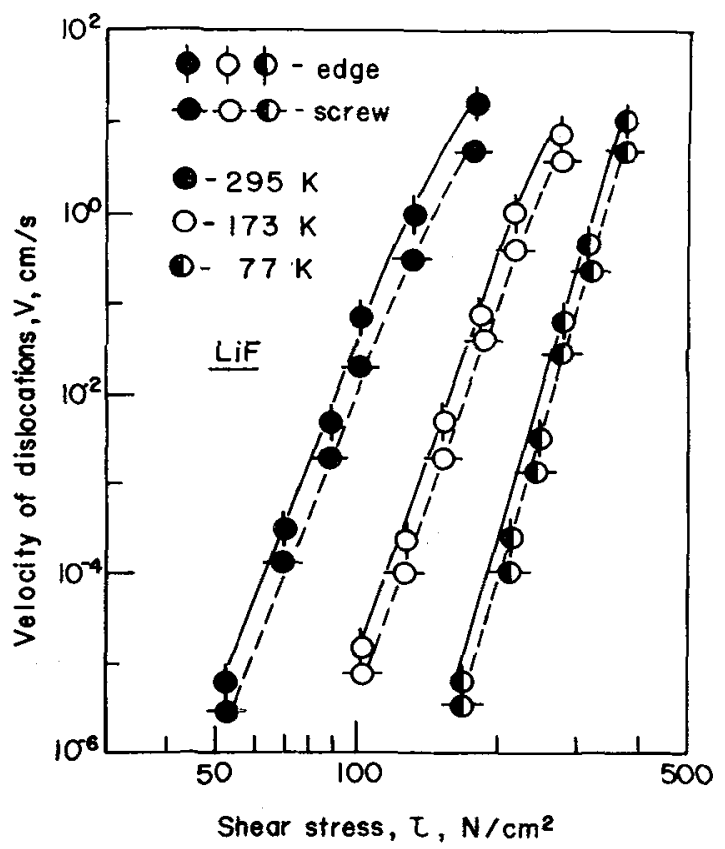

FIg. 3. - Dependence of average velocity $v$ of edge (solid line) and screw (dashed line) dislocations on applied shear stress $\tau$ in $\mathrm{LiF}(\lg \nu-\lg \tau$ scale) at various temperatures.

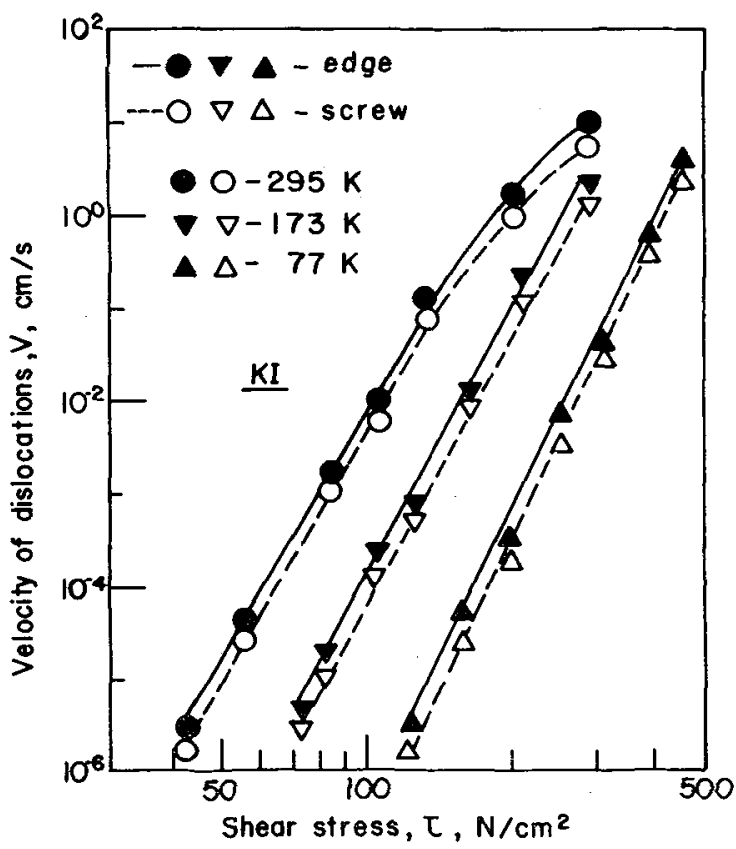

Fig. 4. - Dependence of average velocity $v$ of edge (solid line) and screw (dashed line) dislocations on applied shear stress $\tau$ in $\mathrm{KI}(\lg v$ - $\lg T$ scale) at various temperatures.

The dislocation mobility in the low-velocity region where $v$ in alkali halides is very sensitive to divalent impurities concentration $c_{\mathbf{i}}$ is usually described by the thermally activated process of overcoming impurity barriers by moving dislocation. The average velocity $v$ in this case is given by

$$
v=\frac{S}{I} v \exp \left[-\frac{\Delta H\left(\tau, c_{\mathrm{i}}\right)}{k T}\right]
$$

where $S$ is the mean area swept out by dislocation after overcoming a barrier, $L / 2$ is the mean distance between the barriers, $v$ is the frequency factor and $H\left(\tau, c_{i}\right)$ is the enthalpy of activation. According to expression (2) the dislocation velocity dependences in the low-velocity region should give straight lines in a $\lg v-1 / T$ scale. But as it can be seen from figure 5 the experimental

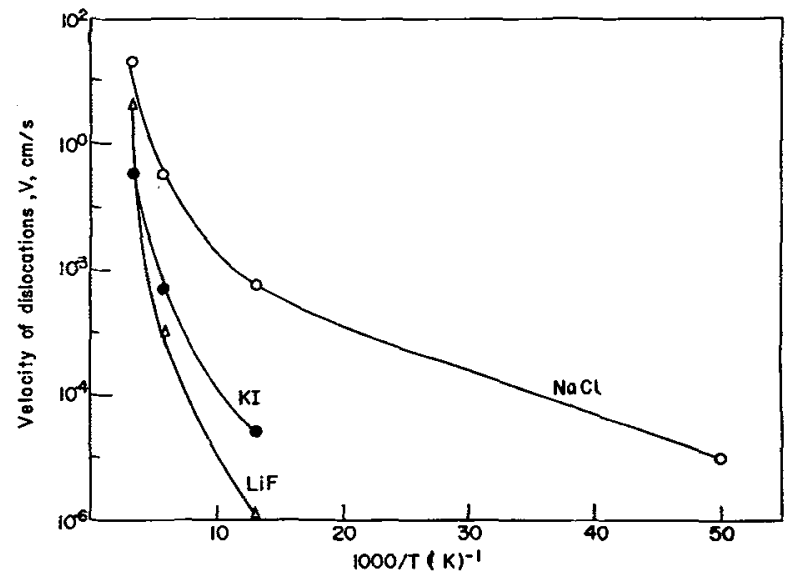

FIG. 5. - Dependence of $\lg v$ (edge type) on $1 / T$ for $\mathrm{NaCl}$ $\left(\tau=150 \mathrm{~N} / \mathrm{cm}^{2}\right), \operatorname{LiF}\left(\tau=150 \mathrm{~N} / \mathrm{cm}^{2}\right)$ and $\mathrm{KI}\left(\tau=150 \mathrm{~N} / \mathrm{cm}^{2}\right)$.

curves for $\mathrm{NaCl}, \mathrm{LiF}$ and $\mathrm{KI}$ are not straight lines on the scale mentioned. The experimental results obtained in [6] were in good agreement with the expression obtained for $v$ using a statistical treatment to dislocation motion in crystal with impurity pinning centers [9]

$$
\begin{aligned}
v=v_{0}\left\{1+\frac{A c_{\mathrm{p}}\left[1-\left(T / T_{0}\right)^{1 / 2}\right]}{\tau}\right\} \times \\
\times \exp \left\{-\frac{A c_{\mathrm{p}}\left[1-\left(T / T_{0}\right)^{1 / 2}\right]}{\tau}\right\}
\end{aligned}
$$

where $v_{0}$ is the dislocation velocity in a crystal without pinning centers, $A$ is a constant of the order of $G$ (shear modulus), $c_{\mathrm{p}}$ is the concentration of pinning centers $\left(c_{\mathrm{p}} \sim c_{\mathrm{i}}\right)$ and $T_{0}$ is the temperature at which breakaway from pinning centers occurs because of thermal fluctuations (see [10]). According to expression (3) dislocation velocity dependences should give straight lines in a $\log \frac{v_{0}}{v}-T^{1 / 2}$ scale, where $v_{0}$ coresponds to an extrapolation of the high-velocity region of the $v(\tau)$ dependence to lower $\tau$ (to the experimental points in the lowvelocity region). As can be seen from figure 6 experimental results for $\mathrm{NaCl}$ are in good agreement with (3) excluding $4.2 \mathrm{~K}$.

In the high velocity region the dislocation mobility is usually described by viscous drag processes and the average velocity is given by

$$
v=\frac{b}{B} \tau,
$$




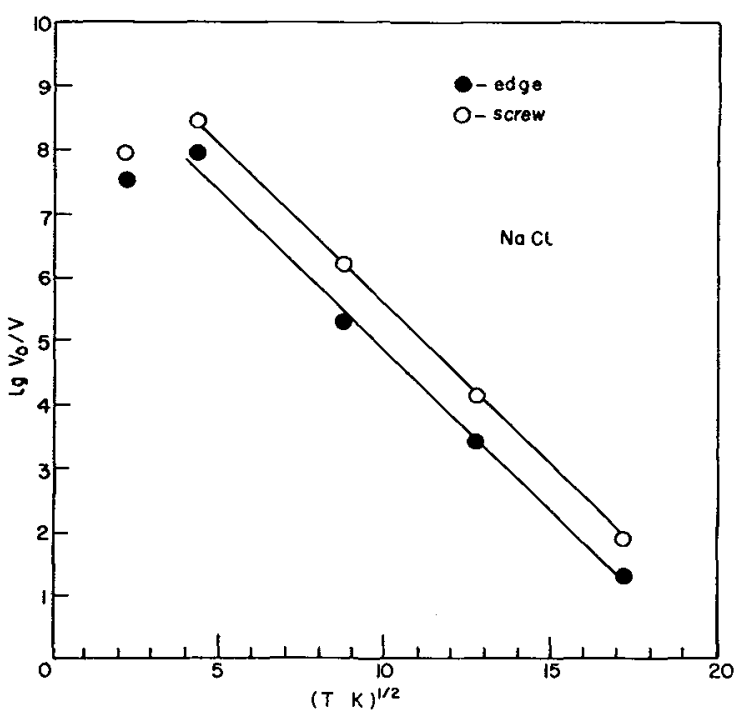

FIG. 6. - Dependence of $\lg v_{0} / v$ on $T^{1 / 2}$ (according to equation (3)) for $\mathrm{NaCl}\left(\tau=150 \mathrm{~N} / \mathrm{cm}^{2}, v_{0}\right.$ corresponds to extrapolation of figure 2 data to lower $\tau$ ).

where $B$ is the viscous drag coefficient. As it can be seen from figures $2 a$ and $2 b$ experimental results obtained in $\mathrm{NaCl}$ for the high-velocity region are in good agreement with expression (4) for viscous dislocation motion. On figure 7 the dependence of viscous drag coefficient $B$, calculated from the linear portion of $v(\tau)$ curves, on temperature in $\mathrm{NaCl}$ is presented. It can be seen from figure 7 that $B$ decreases when temperature decreases and that the decrease is more strongly pronounced when the temperature decreases from 77 down to $4.2 \mathrm{~K}$. This result agrees with various theories predicting a decrease of phonon-dislocation interaction with a temperature decrease (see the recent review [11]).

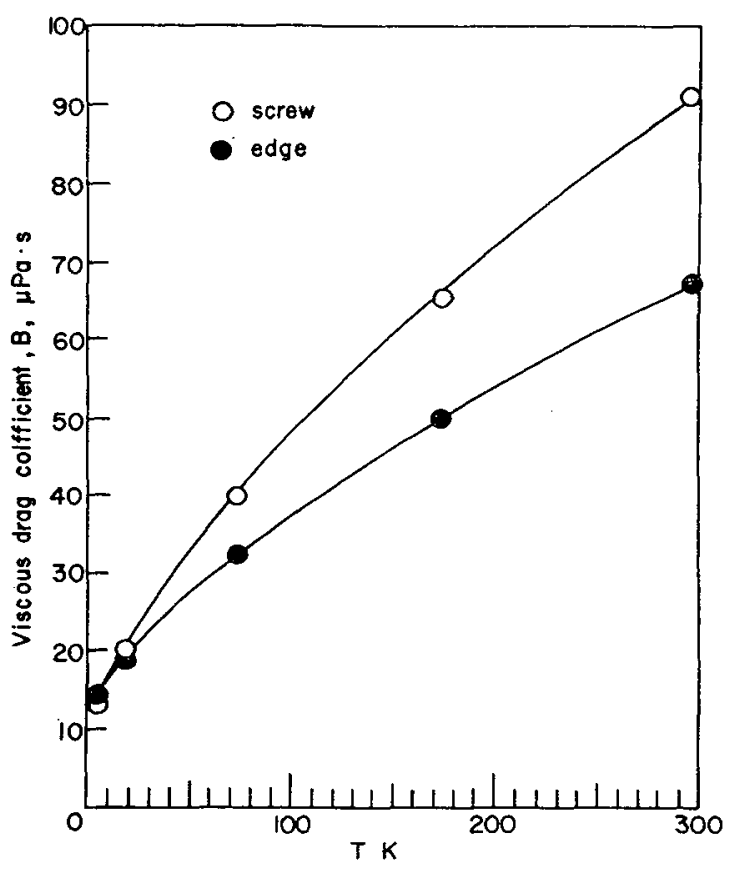

Fig. 7. - Dependence of viscous drag coefficient $B$ on temperature in $\mathrm{NaCl}$ for edge and screw dislocations.
The data for the $v(\tau)$ dependence in $\mathrm{NaCl}$ at $4.2 \mathrm{~K}$ (low-velocity region) are in disagreement not only with expressions (2) and (3) (see Fig. 5 and 6), but with all expressions obtained from various theories for dislocation motion. As it can be seen from figures $1 a$ and $1 b$ in the whole range of velocities the measured $v$ at $4.2 \mathrm{~K}$ are higher then those at $20 \mathrm{~K}$ and there is a wide range of velocities where $v$ at $4.2 \mathrm{~K}$ is even higher then at $77 \mathrm{~K}$. For a wide range of $\tau$, the velocities of dislocations at $4.2 \mathrm{~K}$ are by two orders of magnitude (and more) higher than at the same stress level at $20 \mathrm{~K}$. Even if we take into account that in (2) $v \sim 1 / B[12,13]$ and in (3) $v_{0} \sim 1 / B$ this will give us only a $\sim 1.5$ times increase in the pre-exponential when passing from 20 down to $4.2 \mathrm{~K}$

Granato [14] considered inertial effects (connected with an electron viscous drag coefficient $B_{\mathrm{e}}$ change during a superconducting transition) on overcoming of pinning centers by moving dislocation in a model of a viscous vibration of a loaded dislocation string. It is difficult to use the results obtained in [14] to analyze the present results. In [15] a rougher, but at the same time, more simple model is considered : the kinetic energy of a dislocation segment, directly interacting with the pinning center is taken into consideration. The kinetic energy of such a segment can be expressed as

$$
E_{\mathrm{K}}=\frac{m v_{0}^{2}}{2}=\frac{\pi r^{2} \cdot l \cdot d \cdot v_{0}^{2}}{2}
$$

where $m$ is the mass of the segment, $d$ is the radius of the dislocation core, $l$ is the length of the segment, $d$ is the density of the crystal and $v_{0}$ is the velocity of viscous dislocation motion between pinning centers. Then using the experimental data obtained (Fig. 1 and 7), taking $r=2 b$ and $l / 2=3 b$ at $\tau=240 \mathrm{~N} / \mathrm{cm}^{2}$ we will obtain for kinetic energy of screw dislocations

$$
E_{\mathrm{K}}^{\mathrm{s}}=3.3 \times 10^{-3} \mathrm{eV}(\text { at } 295 \mathrm{~K})
$$

and

$$
E_{\mathrm{K}}^{\mathrm{s}}=0.22 \mathrm{eV}(\text { at } 4.2 \mathrm{~K})
$$

and for kinetic energy of edge dislocations $E_{\mathrm{K}}^{\mathrm{e}}=4.5 \times 10^{-3} \mathrm{eV}($ at $295 \mathrm{~K})$ and $E_{\mathrm{K}}^{\mathrm{e}}=0.2 \mathrm{eV}($ at $4.2 \mathrm{~K})$. The estimated values of $E_{\mathrm{K}}$ for $4.2 \mathrm{~K}$ are of the same order of magnitude as the binding energy between dislocations and pinning centers produced by divalent impurities in alkali halides (see measurements in room temperature region in $\mathrm{LiF}$ [1] and in $\mathrm{KBr}$ [16] and calculations made recently in [17]). It can be conclude that the kinetic energy of viscous motion of dislocation segments can be of great importance in overcoming pinning centers at low temperatures. Measurements of the $v(\tau)$ dependences at helium temperatures in various crystals both in the low and high-velocity regions are of great interest.

Data on the temperature dependences of the critical resolved shear stresses $\tau_{\mathrm{s}}$ for the same pure $\mathrm{NaCl}, \mathrm{LiF}$ and $\mathrm{KI}$ are presented in figure 8 . The temperature 


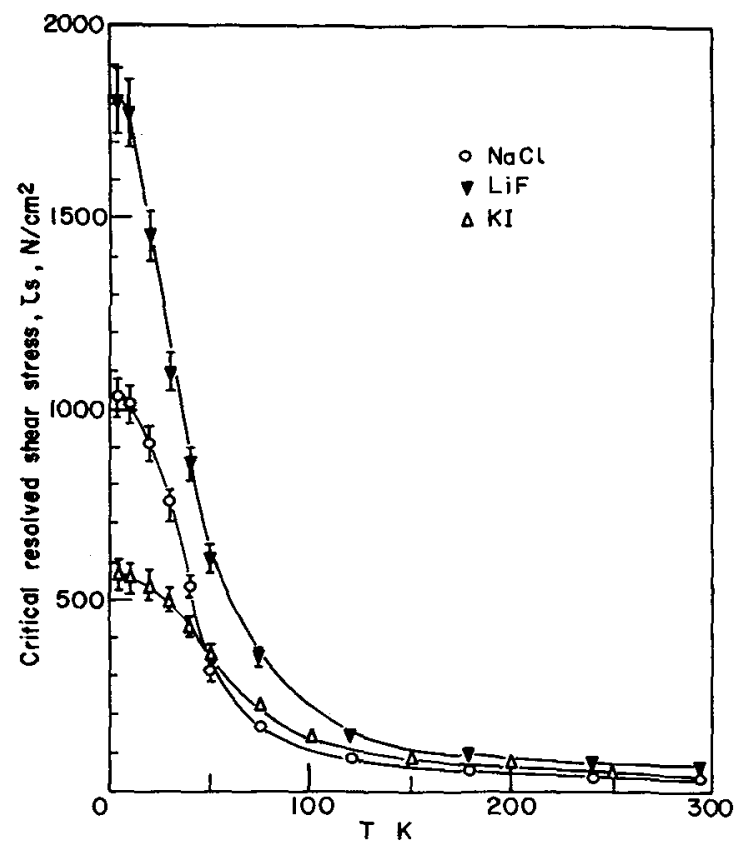

Fig. 8. - Dependence of critical resolved shear stress $\tau_{s}$ on temperature in $\mathrm{NaCl}, \mathrm{LiF}$ and $\mathrm{KI}$.

dependences of $\tau_{\mathrm{s}}$ for pure $\mathrm{KCl}, \mathrm{KBr}$ and $\mathrm{RbI}$ are presented in figure 9. It can be seen from these curves that for all crystals investigated there are two regions of temperature: from room temperature down to $\sim 100 \mathrm{~K}$ and at very low temperatures, where $\tau_{\mathrm{s}}$ is insensitive to temperature. In table I data for dislocation velocities $v\left(\tau_{s}\right)$, corresponding to the critical resolved shear stress $\tau_{\mathrm{s}}$ at various temperatures for $\mathrm{NaCl}, \mathrm{LiF}$ and $\mathrm{KI}$ investigated are listed. It can be seen from the table that $v\left(\tau_{\mathrm{s}}\right)$ increases when the temperature decreases. For $\mathrm{NaCl}$ at $4.2 \mathrm{~K}$ the value $v\left(\tau_{\mathrm{s}}\right)$ is very high. Making an estimate of $\rho$, using equation (1) and taking $\dot{\varepsilon}_{\mathrm{p}} \approx 2 \times 10^{-5} \mathrm{~s}^{-1}, b \approx 4 \times 10^{-8} \mathrm{~cm}$ and $v\left(\tau_{\mathrm{s}}\right) \approx 3 \times 10^{4} \mathrm{~cm} / \mathrm{s}$ we obtain $\rho \ll 1$ at $\tau_{\mathrm{s}}$ in $\mathrm{NaCl}$ at $4.2 \mathrm{~K}$. This means that the density of mobile dislocations during plastic deformation of $\mathrm{NaCl}$ at $4.2 \mathrm{~K}$ is very low (since $\dot{\varepsilon}_{\mathrm{p}}>0$ only when $\tau \geqslant \tau_{\mathrm{s}}$ ); it also means that the plastic deformation is controlled (and the $\tau_{\mathrm{s}}$ on temperature dependence is determined) at low

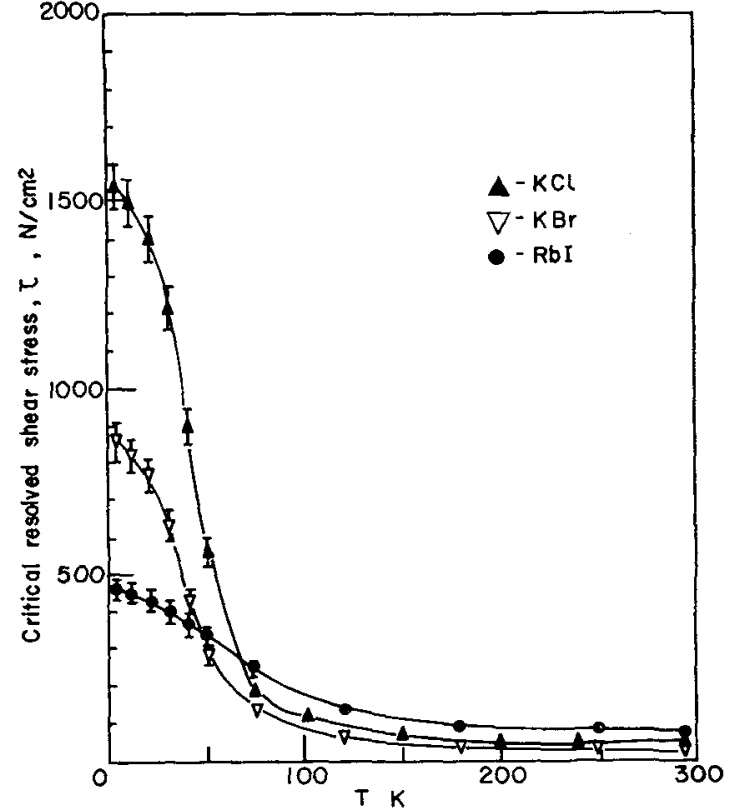

FIG. 9. - Dependence of critical resolved shear stress $t_{s}$ on temperature in $\mathrm{KCl}, \mathrm{KBr}$ and $\mathrm{RbI}$.

temperatures not by the dislocation motion process but by processes and mechanisms of dislocation multiplication. In such a case an investigation of the $\tau_{s}(T)$ dependences at various strain rates makes it possible to determine the parameters of dislocation multiplication mechanisms.

A weak temperature dependence of $\tau_{\mathrm{s}}$ in the region of room temperature is usually observed for pure alkali halides and other pure crystals. Temperature independent regions of $\tau_{\mathrm{s}}$ at very low temperatures have been also observed in pure W [18]. In alkali halides this $\tau_{\mathrm{s}}$ independency on $T$ is probably connected with a change of dislocation multiplication mechanism in these crystals at low temperature, for instance, from multiple cross-slip to multiplication of dislocations on stress concentrators. A decrease of the viscous drag coefficient $B$ at low temperatures can also give a growth in the number of dislocation loops of critical size from thermal or stress fluctuations.

TABLE I

Dislocation velocities $v\left(\tau_{\mathrm{s}}\right)$, corresponding to the critical resolved shear stress, $\tau_{\mathrm{s}}$, at various temperatures in $\mathrm{NaCl}, \mathrm{LiF}$ and $\mathrm{KI}$ crystals

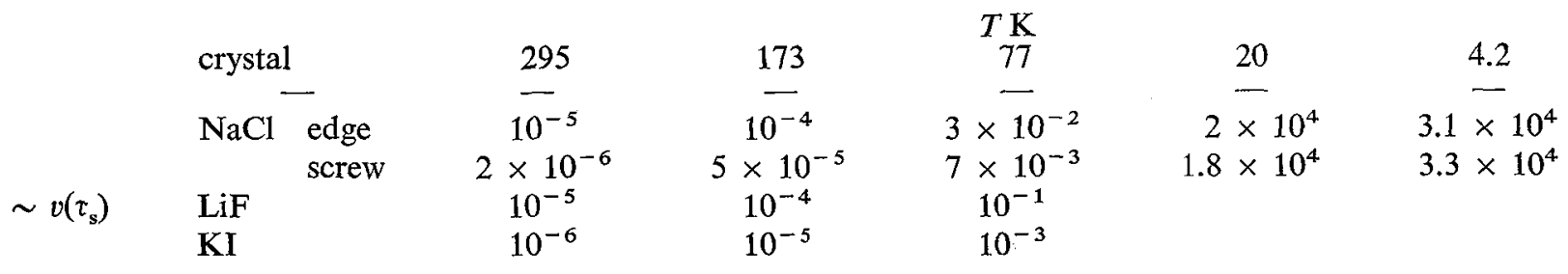




\section{References}

[1] Johnston, W. G. and Gilman, J. J., J. Appl. Phys. 30 (1959) 129.

[2] Gutmanas, E. Y., Nadgornyi, E. M. and Stepanov, A. V., Sov. Phys.-Solid State 5 (1963) 743 ;

Gutmanas, E. Y. and NadgornY, E. M., Sov. Phys.Solid State 10 (1969) 1799 ;

Gutmanas, E. Y., ph. d. Thesis, Moscow (1970).

[3] Pariskir, V. B., Lubenets, V. S. and Startsev, V. I., Sov. Phys.-Solid State 8 (1966) 976.

[4] Lubenets, S. V. and Startsev, V. I., Sov. Phys.-Solid State 10 (1968) 15.

[5] Argon, A. S. and Padawer, G. E., Phil. Mag. 25 (1972) 1073.

[6] Bobrov, V. S., Gutmanas, E. Y. and Kisel, V. P., Physical Processes of Plastic Deformation at Low Temperatures, Conf. Abstracts, Kharkov (1971), p. 32.

[7] Ermakov, G. A. and Nadgorny, E. M., Sov. Phys.Solid State 13 (1971) 513.
[8] Gutmanas, E. Y. and Nadgornyi, E. M., Sov. Phys. Crystallogr. 13 (1968) 85.

[9] Gutmanas, E. Y. and Nadgornyi, E. M., Sov. Phys.Solid State 10 (1969) 1805.

[10] Foreman, A. J. E. and Makin, M. J., Phil. Mag. 14 (1966) 911.

[11] Al'shits, V. I. and Indengom, V. L., Sov. Phys.-Uspekhi 18 (1975) 1.

[12] Indenbom, V. L. and Estrin, Yu. Z., Phys. Status Solidi (a) 4 (1971) K 37.

[13] Natsik, V. S., Sov. Phys.-JETP 34 (1972) 1359.

[14] Granato, A. V., Phys. Rev. B 4 (1971) 2196.

[15] Gutmanas, E. Y., Phil. Mag. to be published.

[16] PariskiI, V. B. and Tret'Yak, A. I., Sov. Phys.-Solid State 9 (1968) 1933.

[17] IsHII, K., Phil. Mag. 33 (1976) 909.

[18] Oku, T. and Galligan, J. M., Phys. Rev. Lett. 22 (1969). 596.

\section{DISCUSSION}

R. W. WHITWORTH. - The anomalous behaviour of the dislocation velocity in $\mathrm{NaCl}$ below $20 \mathrm{~K}$ is very interesting because anomalies have also been observed in the charge carried by dislocations in this temperature ränge (Stuart, R. A. and Whitworth, R. W., Phil. Mag. 15 (1967) 1057 and FrÖhliCh, F. and SeIfERT, P., Phys. Stat. Sol. 25 (1968) 303). These effects may be related to impurities, particularly anions.
Could you comment on the purity of your specimens?

E. Y. Gutmanas. - The total content of divalent impurities present including anions $\mathrm{O}_{2}$ and $\mathrm{S}_{2}$ did not exceed $10 \mathrm{ppm}$ for $\mathrm{NaCl}$ crystals. There is no enough reason to relate the anomalous behavior of the dislocation velocity in $\mathrm{NaCl}$ below $20 \mathrm{~K}$ with the charge carried by dislocations. 